\title{
EDITORIAL
}

\section{FOR THE IST NATIONAL CONFERENCE ON COMMUNICATION VOICE AND SWALLOW DISORDERS; 13-15 MARCH 2015}

It was indeed an enormous honour for the College of Speech Language and Hearing Sciences (CSLHS), Ziauddin University to host our country's 1st National Conference on Communication Voice and Swallow disorders (1NCCVS), with distinguished speakers and guests enthusiastically participating from India, England, UAE, America, Sweden, Lahore and Islamabad, endeavouring to bring Pakistan on the world map in the field of Speech Language Pathology and Audiology.

Communication is inherent to our existence; it is the divine blessing that makes us who we are. Language magnanimously characterises the human race and has the power to bind those that share it as a common medium of shared thoughts and information amongst one another. Proficient knowledge and use of multiple languages by people of our world can profoundly affect their socio-cultural beliefs and practices. Human infants are born with the potential to acquire language, which is one of the most miraculous human abilities that encompasses sensory, neuromotor, psycholinguistic, social and cognitive skills.

To speak or talk is easily taken for granted just as to drink, eat, chew and swallow; until one of our fellow beings is either unable to eat/swallow properly or has inappropriate verbal communication skills! As a society we seldom desist from out casting children presenting with autism, global developmental delay or hearing loss, finding it difficult to develop a socio-communicative relationship with them or their families. People with a stutter often become the brunt jokes and ridicule in the electronic media and cinema (sinfully)!

A communication impediment can be debilitating enough to alienate a person (adult or child) from his loved ones, as its manifestation presents varying degrees of inability to speak; or understand what is spoken; or both. The impact may prevent a child from being accepted for mainstream academic instruction at school, especially in the third world where individuals are often deprived of their basic human rights of having sufficient food, access to health care services and education.

Although Pakistan signed the United Nations Convention on the Rights of Persons with Disabilities (UNCRPD or Convention) in 2008 and ratified it in July 2011; we still need to see the implementation of several of its articles here. In its Article 24 on Education, the Convention declares that the dignity and integrity of all persons with different abilities must be held in high esteem; and that access to education is a basic right of every child indiscriminate of the (communication) deficit that she/he presents with; in comparison with typically developing children. They must be given a fair chance to succeed in their academic endeavours side by side with typically developing peers in inclusive educational settings. To facilitate their success they must be provided with all the necessary support through modifications in the school's infrastructure as well as through well qualified and trained human resource. All means of communication must be employed in accordance with the need of the child; such as verbal communication, non-verbal; or alternative and augmentative means of communication such as use of sign language, or the Picture Exchange Communication System (PECS) with the school adopting the same communicative modes to ensure the child receives adequate social, and linguistics stimulation. Pakistan must modify its school curricula to lay the foundations of inclusive education.

Adults having a communication deficit could be curtailed from earning a substantial living to support their families; in other words there could be financial, physical, as well as emotional dependence, upon the caregivers. The aim of speech language therapy is to provide Quality of Life to the patient, by ensuring that basic needs are first met, followed by an appropriate hierarchy of increments or advances in therapeutic goals, leading to maximal self sufficiency and good adjustment in society.

Early intervention (El) which includes early detection as well as treatment of a speech, language, hearing, feeding or swallowing disorder is the key to success with most patients, Therefore, El would mean that the chronological age for children with congenital disorders would be under the age of two years, whereas for adults it would be soon after the morbidity occurs.

The picture began to change in Pakistan with the commencement of INCCVS, as we stood at the threshold 
of bringing about beautiful renaissance in our attitudes towards people with communication impediments. The vision of Ziauddin University is to alleviate the suffering and sadness of all with a congenital or acquired speech, language, hearing, voice or swallow disorder, by shaping their communication skills to the best of their potentials. The CSLHS strives ahead to achieve this goal, endeavouring to provide our country with human resource in the professions of speech language pathology and audiology, thus, causing an evolution in these fields, with the creation of new researches about methods and tools of assessment, and treatment of communication disorders, requiring collaborative work from professionals of various scientific realms. Working in Pakistan we realise that our challenges are many; and we are few in number to fulfil the gigantic demand in the sphere of developing indigenous Pakistani tools of language and speech assessment. We also need Alternative - Augmentative Communication aides, which are linguistically and culturally relevant to our people. This requires the standardization of linguistic components in the several languages spoken in Pakistan, as well as in Urdu, through research of the lexicon, dialect and style of native speakers.

The CSLHS aims to be at par with global developments in our field; through our individual and collective roles with the patients we see, with the valuable inculcation of scientific realms in speech and language impediments of organic and non-organic origin as well as problems of feeding, swallowing and voice disorders across all age groups.

\section{Amina Siddiqui}

Chair Person of 1 NCCVS

Assistant Editor, Pakistan Journal of Rehabilitation

Principal, CSLHS

Ziauddin University 